\title{
Diastereoisomeric diversity dictates reactivity of epoxy groups in limonene dioxide polymerization
}

\author{
M. Soto, K. Koschek* \\ Fraunhofer Institute for Manufacturing Technology and Advanced Materials (Fraunhofer IFAM) Wiener Strasse 12, \\ 28359 Bremen, Germany
}

Received 13 November 2017; accepted in revised form 30 January 2018

\begin{abstract}
Limonene dioxide (LDO) has the potential to find a wide application as a bio-based epoxy resin. Its polymerizations by catalyzed ring-opening, and by polyaddition with diamines were compared with the polymerizations of the commercial epoxy resins bisphenol-A diglycidyl ether (BADGE), and 3,4-epoxycyclohexylmethyl-3',4'-epoxycyclohexane carboxylate (ECC). Differential scanning calorimetry (DSC) studies showed that LDO polymerizations suffer in all cases studied from incomplete conversions. Nuclear magnetic resonance (NMR) studies revealed that in cis-isomers of LDO the internal epoxide rings were not reacting. The low reactivity of this epoxide group was explained by mechanistic considerations making use of the Fürst-Plattner rule, or trans-diaxial effect. Due to diastereomeric diversity approximately one-fourth of epoxide groups present in LDO could not react. Therefore, a diastereoselective epoxidation of limonene could provide a fully reactive bio-based epoxy resin.
\end{abstract}

Keywords: biopolymers, thermosetting resins, thermal properties

\section{Introduction}

Nowadays most bio-extraction procedures of renewable feedstock are accompanied with side products that often are considered as waste. Examples include lignin found in black liquor from cellulose pulping, grape-seed oil derived from wine production, and orange oil produced as by-product of orange and other citrus juice production [1-3]. Their valorization would contribute to a profitable sustainable economy.

Essential oils originating from mechanical pressing of citrus fruits peel are mainly composed of $R$-limonene (95 and 65 in orange and lemon oils, respectively), which can be isolated by distillation $[4$, 5]. Most parts of the 50 to 75 million tons $R$-limonene produced per year are used as fragrance and as solvent [6]. The unsaturated bonds in limonene can be converted to one or two epoxide rings [5]. Limonene oxide was used to prepare bio-based polycarbonates with interesting thermal and optical properties by alternating copolymerization with $\mathrm{CO}_{2}[7,8]$. Limonene dioxide (LDO) was used as starting point for nonisocyanate polyurethane [6]. In the photopolymerization of oxetane, LDO in combination with sulfonium salts extremely reduced the induction time ('kick-starting') [9].

Due to the presence of two epoxide rings, LDO features a high potential to be used as bio-based epoxy monomer to form thermosetting materials. In a series of studies, Lalevée and coworkers [10,11] reported a very fast sunlight induced ring-opening polymerization of LDO via a 'free radical promoted cationic polymerization'. The centerpiece was a photoinitiating system based on a silyl radical. That initiating systems allowed for final conversions of $c a$. $80 \%$ and yielded tack free materials [12]. Crivello et al. [13] developed a related initiating system based on

*Corresponding author, e-mail: katharina.koschek@ifam.fraunhofer.de (C) BME-PT 


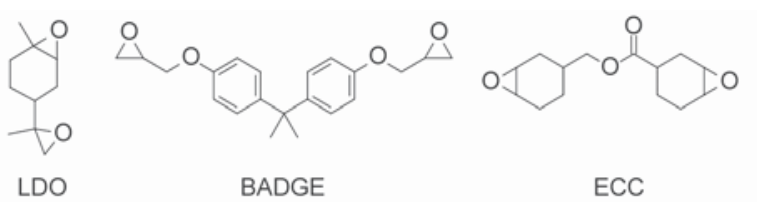

Figure 1. Bifunctional epoxides used in this study. Limonene dioxide (LDO), diglycidyl ether of bisphenol-A (BADGE), and 3,4-epoxycyclohexylmethyl-3',4'epoxycyclohexane carboxylate (ECC).

titanocene chemistry for conventional epoxy based monomers, which was mentioned to work as well with LDO. All studies dealing with LDO describe that LDO polymerization suffers from incomplete conversions. The LDO reactivity itself, however, was not addressed and studied so far.

Therefore, this contribution attempts to gain insight into the reactivity of LDOs endocyclic and terminal epoxide groups. The ring-opening polymerization and polyaddition of LDO in presence of amines were studied in comparison to the bisphenol-A diglycidyl ether (BADGE) and 3,4-epoxycyclohexylmethyl3',4'-epoxycyclohexane carboxylate (ECC) representing LDOs terminal and endocyclic epoxy groups, respectively (Figure 1). This study shows that LDOs reactivity depends on its structural composition and points to what would be needed for LDO application as a fully bio-based epoxy resin.

\section{Experimental}

\subsection{Materials}

Limonene dioxide (LDO) was obtained from Arkema (Düsseldorf, Germany) as isomeric mixture. Boron trifluoride ethylamine complex, 4,7,10-trioxa-1,13tridecanediamine, 1,6-diaminohexane and isophorone diamine were purchased from Sigma-Aldrich (Steinheim, Germany) and used as received. Bisphenol-A diglycidyl ether (BADGE) was purchased as Araldite GY250 from Huntsman Advanced Materials (Bergkamen, Germany) with $180 \mathrm{~g} \cdot \mathrm{eq}^{-1} \cdot 3,4$-Epoxycyclohexylmethyl-3',4'-epoxycyclohexane carboxylate (ECC) was purchased as Omnilane OC 2005 from IGM resins (Krefeld, Germany). Acetonitrile (99.5\%) was purchased from TCI Chemicals (Eschborn, Germany).

\subsection{Measurements}

Proton nuclear magnetic resonance $\left({ }^{1} \mathrm{H}\right.$ NMR $)$ spectra were carried out at room temperature with a Bruker Avance NB $200 \mathrm{MHz}$ with 32-64 scans. Chemical shifts $(\delta)$ were reported in parts per million [ppm] using the solvent residual peak as reference. Differential scanning calorimetry (DSC) measurements were carried out in sealed aluminum pans in a nitrogen atmosphere with a modulated thermal analyzer DSC 2920 CE, TA Instruments, within a temperature range of 20 to $300^{\circ} \mathrm{C}$.

\subsection{Catalyzed ring-opening polymerization}

To limonene dioxide $(0.66 \mathrm{~mL}, 4.4 \mathrm{mmol})$ a boron trifluoride ethylamine complex solution $(0.5 \mathrm{~mL}$, $0.8 \mathrm{M}$ in acetonitrile) was added. The solvent was evaporated using a nitrogen stream while stirring. Afterwards, the mixture was cured for one hour at $90^{\circ} \mathrm{C}$ and for three hours at $120^{\circ} \mathrm{C}$ to yield a brownish-red solid with a tacky surface. Ring-opening polymerizations of BADGE (1.6 g, $4.4 \mathrm{mmol})$ and ECC $(0.95 \mathrm{~mL}, 4.4 \mathrm{mmol})$ were performed according to the same procedure using the same formulation.

\subsection{Polyaddition reaction with an amine hardener}

LDO (1.0 mL, $6.7 \mathrm{mmol})$ and 4,7,10-trioxa-1,13-tridecanediamine $(0.74 \mathrm{~mL}, 3.4 \mathrm{mmol})$ were mixed and reacted at room temperature for $24 \mathrm{~h}$, at $60^{\circ} \mathrm{C}$ for $6 \mathrm{~h}$ and further $6 \mathrm{~h}$ at $120^{\circ} \mathrm{C}$. A highly viscous, dark-orange colored fluid was obtained. Polyaddition of BADGE and ECC with 4,7,10-trioxa-1,13-tridecanediamine was performed analogously.

\section{Results and discussion}

The reactivity of LDO was compared with that of the bifunctional monomers BADGE and ECC. In these monomers, both epoxide groups are of the same nature. BADGE has two terminal epoxides and ECC two endocyclic epoxide groups. Endocyclic epoxide groups are usually cured via UV or thermal initiated ring-opening polymerization using an anionic catalyst (e.g. imidazole, tertiary amine) or a Lewis acid catalyst (e.g. boron trifluoride). Terminal epoxides are cured at room temperature by polyaddition reaction with polyfunctional nucleophiles as hardeners (e.g. amines, anhydrides, acids, alcohols and thiols), whereas non-terminal epoxides require activation with a catalyst or higher temperatures for the polyaddition [14].

In contrast, LDO contains two different epoxide groups, namely one endocyclic epoxide and a terminal one. Therefore, ring-opening polymerization and polyaddition experiments were performed as different reactivities for each epoxide in LDO would be expected. 


\subsection{Catalyzed ring-opening polymerization}

In a first step, the thermal behavior of the neat monomers BADGE, ECC and LDO was characterized performing differential scanning calorimetry (DSC). All monomers showed no exothermic signal corresponding to polymerization or other ring-opening reactions up to $250^{\circ} \mathrm{C}$. In case of LDO an endothermic signal was observed with $T_{\max }$ at $187^{\circ} \mathrm{C}\left(T_{\text {onset }}=\right.$ $\left.142.3^{\circ} \mathrm{C} ; \Delta H_{\mathrm{N}}=50.5 \mathrm{~kJ} \cdot \mathrm{mol}^{-1}\right)$ indicating the boiling point (Figure 2).

In a second step, the polymerization behavior of the monomers was studied with DSC in presence of boron trifluoride ethylamine complex as a Lewis acid catalyst which is known to activate the catalytic ring-

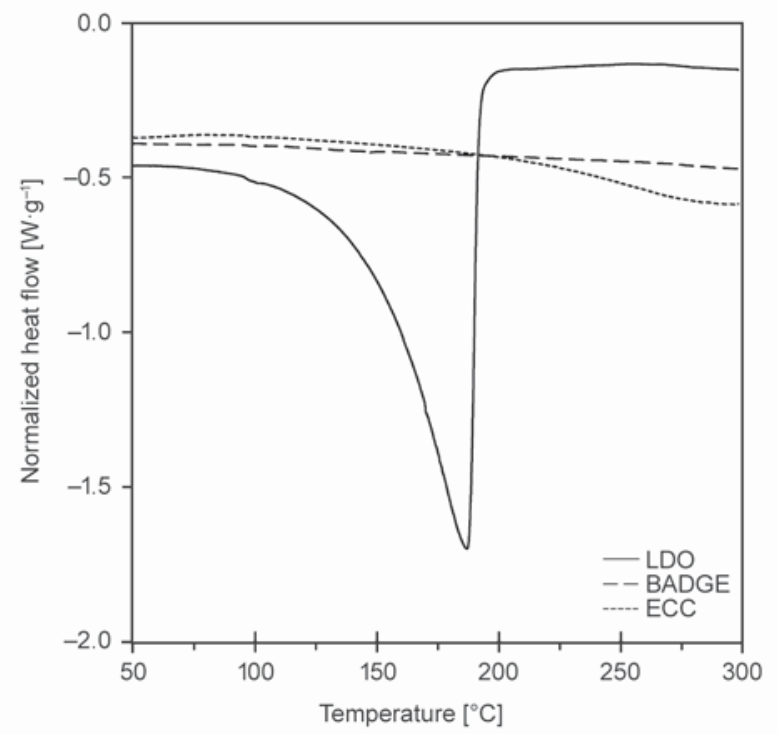

Figure 2. DSC thermograms of LDO, BADGE and ECC performed with a heating rate of $10 \mathrm{~K} \cdot \mathrm{min}^{-1}$.

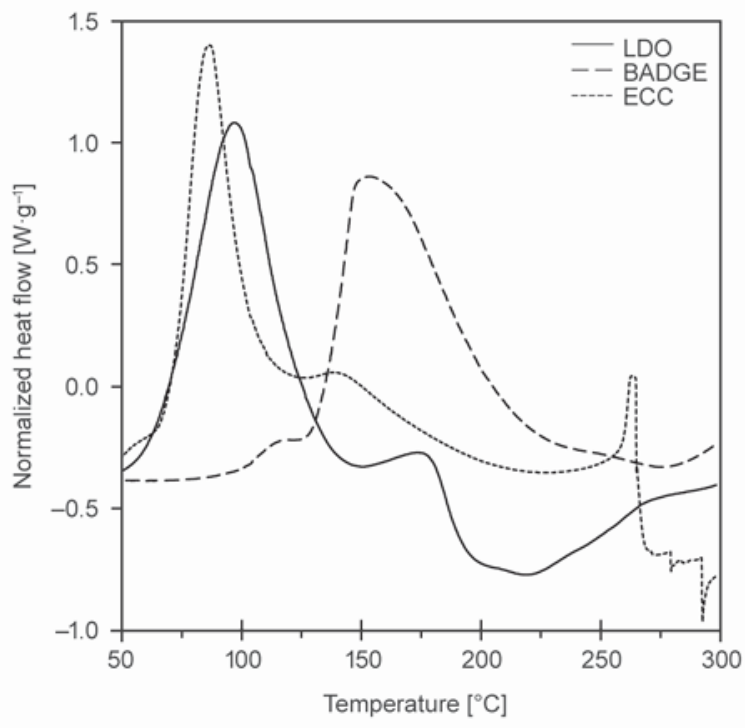

Figure 3. DSC thermograms of LDO, BADGE and ECC containing $10 \mathrm{~mol} \%$ of $\mathrm{BF}_{3} \cdot \mathrm{NH}_{2}$ Et performed with a heating rate of $10 \mathrm{~K} \cdot \mathrm{min}^{-1}$.
Table 1. Summary of DSC results of catalytic ring-opening polymerization of LDO, BADGE and ECC containing $10 \mathrm{~mol} \%$ of $\mathrm{BF}_{3} \cdot \mathrm{NH}_{2}$ Et performed with a heating rate of $10 \mathrm{~K} \cdot \mathrm{min}^{-1}$.

\begin{tabular}{|l|c|c|c|}
\hline \multirow{2}{*}{ Monomer } & $\begin{array}{c}\boldsymbol{T}_{\text {onset }} \\
{\left[{ }^{\circ} \mathbf{C}\right]}\end{array}$ & $\begin{array}{c}\boldsymbol{T}_{\text {peak }} \\
{\left[{ }^{\circ} \mathbf{C}\right]}\end{array}$ & $\begin{array}{c}\Delta \boldsymbol{H}_{\mathbf{N}} \text { Total } \\
{\left[\mathbf{k J} \cdot \mathbf{m o l}^{-1} \mathbf{l}\right.}\end{array}$ \\
\hline \multirow{2}{*}{ LDO $^{\mathrm{b}}$} & 65 & 97 & 64 \\
\cline { 2 - 4 } & 140 & 178 & - \\
\hline \multirow{2}{*}{ BADGE } & 104 & 114 & 149 \\
\cline { 2 - 4 } & 134 & 154 & - \\
\hline \multirow{2}{*}{ ECC } & 71 & 87 & 126 \\
\cline { 2 - 4 } & 129 & 138 & - \\
\hline
\end{tabular}

${ }^{a}$ Total curing enthalpy as the sum of the two exothermic signals per mol epoxide group.

${ }^{b}$ Overlap with LDO boiling event was neglected.

opening polymerization of epoxide monomers, as well as the addition of nucleophiles as ethanol to LDO [15-17]. DSC thermograms of the three monomers BADGE, ECC and LDO in presence of $10 \mathrm{~mol} \%$ of $\mathrm{BF}_{3} \cdot \mathrm{NH}_{2} \mathrm{Et}$ are depicted in Figure 3 and summarized in Table 1. LDO and ECC exhibited a major exothermal peak with an onset temperature around $70^{\circ} \mathrm{C}$ (LDO $T_{\text {onset }}=65^{\circ} \mathrm{C}$; ECC $T_{\text {onset }}=71^{\circ} \mathrm{C}$ ) corresponding to the ring-opening reaction of epoxycyclohexane. Additionally, LDO showed a second exothermic signal with a lower enthalpy and a $T_{\text {onset }}$ of $140^{\circ} \mathrm{C}$. In that temperature range BADGE reacted as well $\left(T_{\text {onset }}=134^{\circ} \mathrm{C}\right)$ which was attributed to the ring-opening reaction of the terminal epoxide group. Comparing the reaction enthalpies per mol of epoxide groups, LDO reacted with $\Delta H_{\mathrm{N}}=64 \mathrm{~kJ} \cdot \mathrm{mol}^{-1}$ which corresponds to approx. half of the reaction enthalpy of ECC $\left(\Delta H_{\mathrm{N}}=126 \mathrm{~kJ} \cdot \mathrm{mol}^{-1}\right)$ and BADGE $\left(\Delta H_{\mathrm{N}}=149 \mathrm{~kJ} \cdot \mathrm{mol}^{-1}\right)$ (Figure 3, Table 1). That indicated that LDO yields an incomplete conversion in presence of boron trifluoride ethylamine as a Lewis acid catalyst.

Based on the DSC results, LDO, BADGE and ECC samples were polymerized with boron trifluoride ethylamine complex using a standard polymerization procedure $\left(3 \mathrm{~h}\right.$ at $90^{\circ} \mathrm{C} ; 1 \mathrm{~h}$ at $\left.120^{\circ} \mathrm{C}\right)$. While BADGE and ECC provided hard and transparent polymeric materials, LDO formed a sticky semi-transparent one, which is in agreement with the determined incomplete conversion in DSC measurements.

\subsection{Polyaddition reaction with an amine hardener}

Next, the polyaddition reaction of LDO, BADGE and ECC with the primary diamine 4,7,10-trioxa-1,13tridecanediamine was studied. For this, bulk samples 
were prepared by reacting LDO, BADGE and ECC with the primary diamine in stoichiometric ratio at room temperature for 24 hours. BADGE yielded a transparent solid. LDO and ECC, however, showed only a slight viscosity increase after 24 hours at room temperature. Therefore, the temperature was increased to $60^{\circ} \mathrm{C}$ for 6 hours and after that to $120^{\circ} \mathrm{C}$ for further 6 hours in order to promote the reaction. Despite of this, LDO and ECC yielded no solids, but extremely viscous dark fluids. To check for the extent of the reaction, DSC measurements of the bulk samples after reaction were performed (Figure 4).

The solid material derived from BADGE showed no exothermic peak confirming a fully polymerized material. In case of ECC the exothermic peak at $260^{\circ} \mathrm{C}$ showed an autocatalytic post-curing indicating the presence of unreacted epoxides. That was to be expected as endocyclic epoxide groups exhibit a lower reactivity towards amines in comparison to the terminal analogues. In contrast, no exothermic peak appeared at high temperatures after the reaction of LDO and 4,7,10-trioxa-1,13-tridecanediamine. To explore the generality of this result, LDO was reacted under the same conditions with two other diamines, namely 1,6-diaminohexane and isophorone diamine, respectively. In both cases, highly viscous fluids were obtained showing no exothermic peaks in DSC analyses.

Thus, while the reaction of LDO with different diamines either all epoxide groups were converted or the remaining groups suffered from extreme low

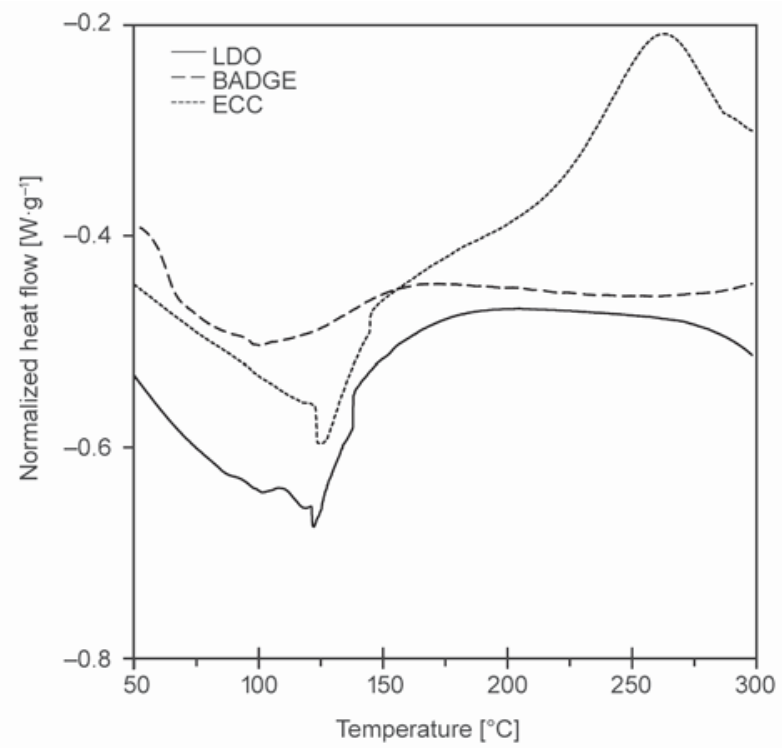

Figure 4. DSC thermograms of LDO, BADGE and ECC after reaction with 4,7,10-trioxa-1,13-tridecanediamine performed with a heating rate of $10 \mathrm{~K} \cdot \mathrm{min}^{-1}$. reactivity lacking autocatalytic post-curing. The viscous fluids obtained after LDO reaction with the various diamines point to oligomer formation instead of the expected cross-linked polymer. In order to better understand the chemical reactivity of LDO, the polymerization was studied using ${ }^{1} \mathrm{H}$ NMR.

\subsection{LDO reactivity explored by ${ }^{\mathbf{1}} \mathrm{H}$ NMR}

Commercial limonene dioxide derives from the natural isomer $R$-limonene by non-diastereoselective epoxidation which generates the epoxycyclohexane as a mixture of cis- and trans-isomers [18]. Epoxidation of the exocyclic double bond provides a chirality center in $\mathrm{C} 8$, increasing the number of diastereomers to a total of four (Figure 5A) that cannot be separated physically [19].

The different peaks in the ${ }^{1} \mathrm{H}$ NMR of commercial LDO were assigned by comparing the relative position of the peaks with signals of isolated isomers reported in the literature [19]. The methyl group located at the external epoxide $\left(\mathrm{CH}_{3}-10\right)$ showed a chemical

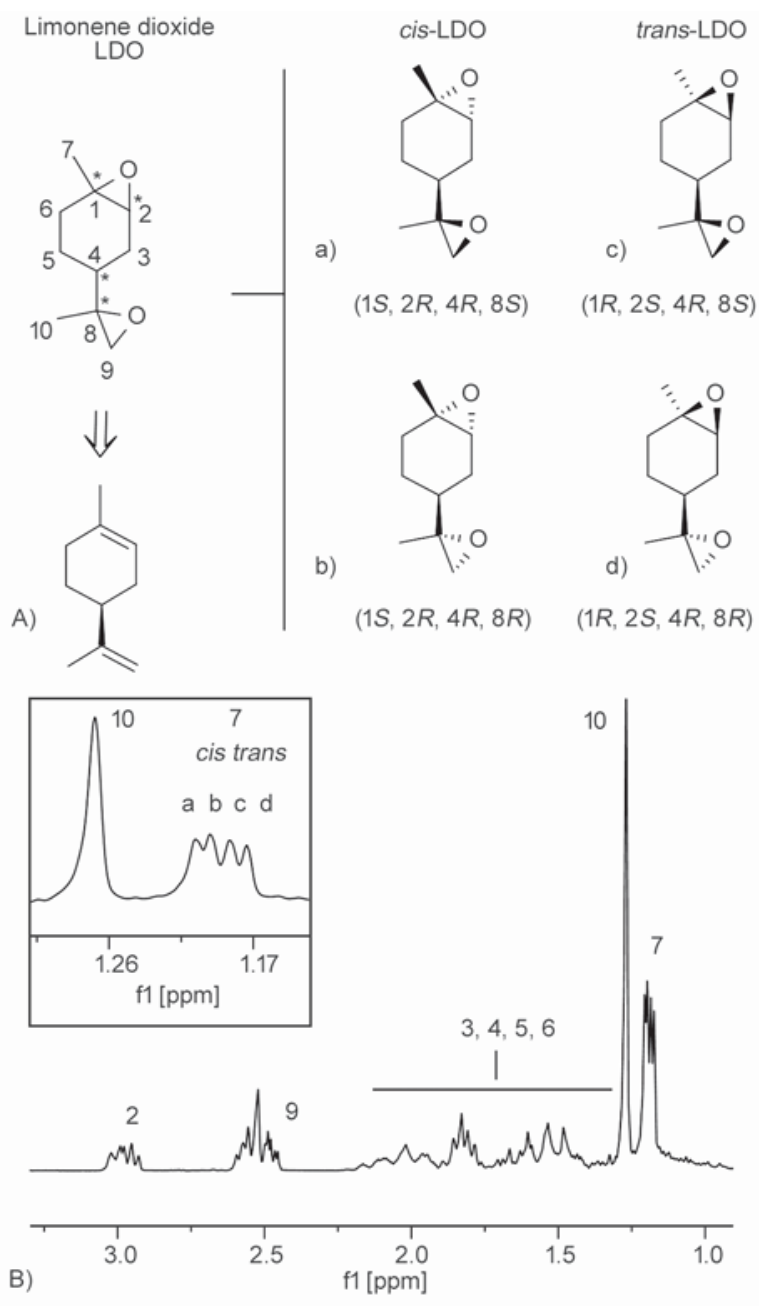

Figure 5. A) LDO isomeric structures; B) ${ }^{1} \mathrm{H}$ NMR of LDO. 
shift at $1.27 \mathrm{ppm}$ for all four isomers (Figure 5B). As it is located outside the cycle, it is not affected by the different conformations of the cyclohexane ring. In contrast, the methyl group at the epoxycyclohexane $\left(\mathrm{CH}_{3}-7\right)$ yielded four different peaks of comparable intensity between 1.17 and $1.21 \mathrm{ppm}$, each one corresponding to one diastereomer.

LDO ring-opening polymerization catalyzed by boron trifluoride ethylamine was studied with ${ }^{1} \mathrm{H}$ NMR at $120^{\circ} \mathrm{C}$ for a maximum of $20 \mathrm{~min}$ as longer reaction times resulted in insoluble fractions. ${ }^{1} \mathrm{H}$ NMR spectra of LDO before and after reaction are depicted in Figure 6 and summarized in Table 2. The reaction of the external epoxide entailed a decrease of methyl group signal with the number 10 . Before polymerization this signal accounted for $52 \%$ of the integral representing the ${ }^{1} \mathrm{H}$ NMR methyl region (from 1.33 to $0.80 \mathrm{ppm}$ ) and afterwards for $23 \%$. Combined signals of the methyl group 7 corresponding to the trans-isomers (Figure 6 signals $\mathrm{c}$ and d, 7-trans) decreased from an initial $20 \%$ integral to a $9 \%$ integral after reaction. Signals corresponding to methyl 7-cis (Figure 6 signals a and b) barely changed, as relative integration remained in the range of $28-29 \%$. Those results indicated that endocyclic epoxides opened in trans-isomers Figure 6 signals $\mathrm{c}$ and $\mathrm{d}$ but not in cis-isomers Figure 6 signals $a$ and $b$.

The fact that the $c i s$-isomeric endocyclic epoxide did not react, explains why LDOs ring-opening polymerization yielded a brittle material with a tacky surface as chain growth and network formation were hindered. That result raised the question if this lack
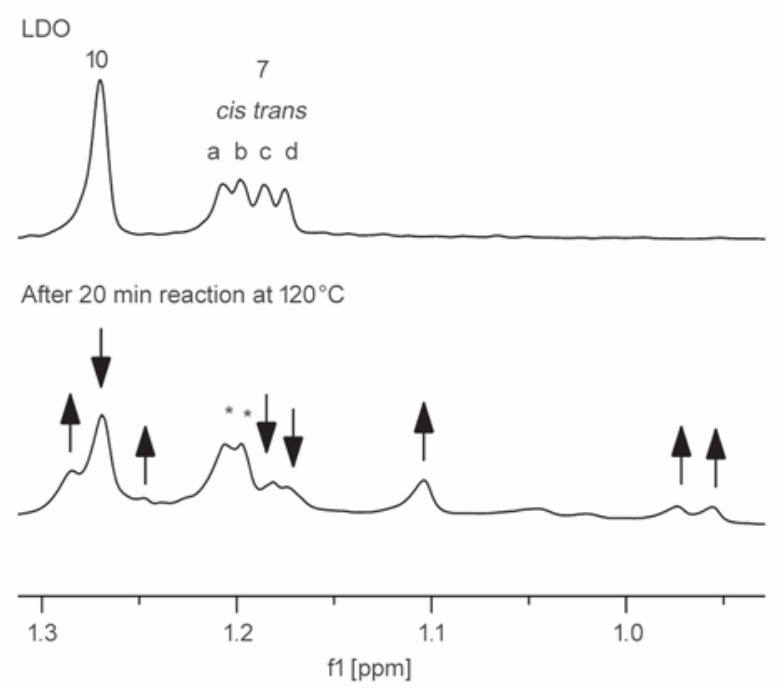

Figure 6. ${ }^{1} \mathrm{H}$ NMR spectra of LDO before and after reaction with $\mathrm{BF}_{3} \cdot \mathrm{NH}_{2} \mathrm{Et}\left(20 \mathrm{~min} ; 120^{\circ} \mathrm{C}\right)$. *non-changing signals.
Table 2. ${ }^{1} \mathrm{H}$ NMR signal assignment and relative integrals in the region $1.33-0.80 \mathrm{ppm}$ of $\mathrm{LDO}$ before and after its reaction with $\mathrm{BF}_{3} \cdot \mathrm{NH}_{2} \mathrm{Et}\left(20 \mathrm{~min} ; 120^{\circ} \mathrm{C}\right)$.

\begin{tabular}{|l|c|c|c|}
\hline \multicolumn{1}{|c|}{ Methyl } & $\begin{array}{c}\boldsymbol{\delta} \\
{[\mathbf{p p m}]}\end{array}$ & $\begin{array}{c}\text { Initial } \\
{[\mathbf{\%}]}\end{array}$ & $\begin{array}{c}\text { Reaction } \\
{[\mathbf{\%}]}\end{array}$ \\
\hline 10 & 1.27 & 52 & 23 \\
\hline 7-cis (7a+7b) & $1.21 ; 1.20$ & 29 & 28 \\
\hline 7-trans (7c+7d) & $1.19 ; 1.18$ & 20 & 9 \\
\hline Other & $1.32-1.28 ; 1.16-0.80$ & 0 & 40 \\
\hline
\end{tabular}

of reactivity exclusively affected the Lewis acid catalyzed ring-opening polymerization or polyaddition reactions with amine hardeners as well. Therefore, polymerization of LDO with the diamine 4,7,10-trioxa-1,13-tridecanediamine was performed at $120^{\circ} \mathrm{C}$ and followed after $20 \mathrm{~min}$ by ${ }^{1} \mathrm{H}$ NMR. Signals of methyl 7 in cis-isomers (Figure 6 signals a and b) did not change significantly, their relative integration barely evolved from initially 29 to final $27 \%$. Integrals of methyl 7-trans (Figure 6 signals $\mathrm{c}$ and d) decreased from initially 20 to $13 \%$ after reaction. These results indicate that the internal epoxy group of cisisomers did not react. Activation of the reaction was attempted using imidazole as nucleophilic catalyst, or, alternatively, boron trifluoride ethylamine complex as Lewis acid catalyst. However, in spite of this activation, internal epoxides showed a similar nonreactivity for the $c i s$-isomers.

\subsection{Implications for the ring-opening reaction of LDO}

All results pointed out that the terminal epoxides were reactive in all isomers, while the endocyclic ones were reactive exclusively in the trans-isomers of LDO (Figure 7).

The Fürst-Plattner rule or trans-diaxial effect could provide an explanation for the diastereoselectivity of this reaction [20]. This rule states that nucleophilic additions to cyclohexene derivatives yield exclusively the trans-diaxial addition product as the reactions only take place if a nucleophile and a leaving group are in trans-diaxial positions. The attack of a nucleophile proceeds fast through a favorable 'chair-like' transition state, while it does not take place in case of an unfavorable 'boat-like' transition state [18]. Thus, the diastereoselectivity is based on conformational differences in the transition states [21].

Regarding limonene derivatives, this fact was exploited in limonene monoxide to prepare chiral auxiliaries by Chrisman et al. [18]. In a mixture of the two $R$-limonene monoxide isomers, the trans-isomer 


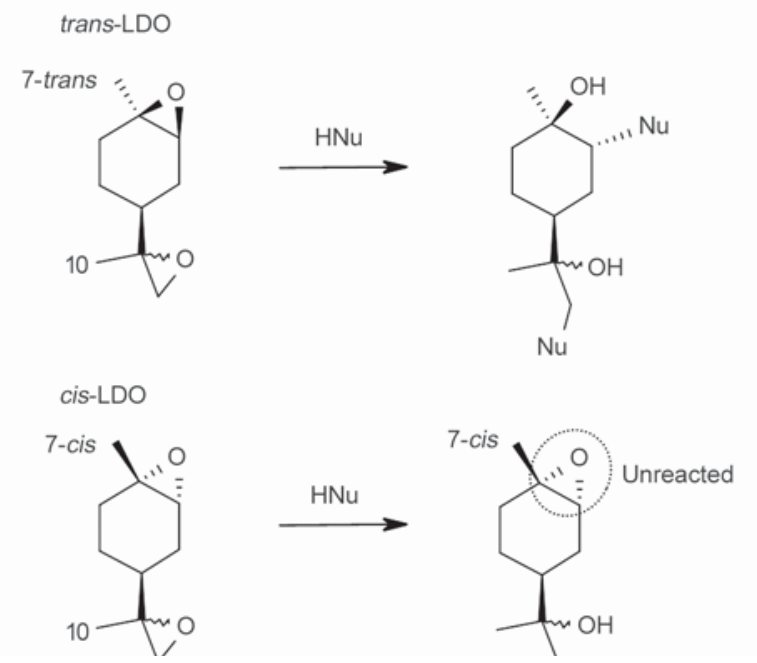

Figure 7. Behavior of trans- and cis-limonene dioxide (LDO) in presence of nucleophiles.

reacted selectively to produce the desired chiral product, whereas the cis-isomer remained unreacted. Extrapolating to LDO, the trans-diaxial effect could explain the low reactivity of the endocyclic epoxy in the cis-isomers of LDO (Figure 8).

A possible mechanism for the ring-opening reaction of LDO applying the Fürst-Plattner rule is presented in Figure 8. The 2-methyloxirane-2-yl group in position 4 will remain in equatorial position due to its high steric hindrance, limiting the number of conformations the cyclohexane ring could adopt. The nucleophilic attack on the endocyclic epoxide should take place at the less substituted carbon atom from the opposite side of the oxirane ring in a SN2-like mechanism. According to the Fürst-Plattner rule that attack would generate a transition state (TS) in which the nucleophile and the oxygen atom occupy axial positions.

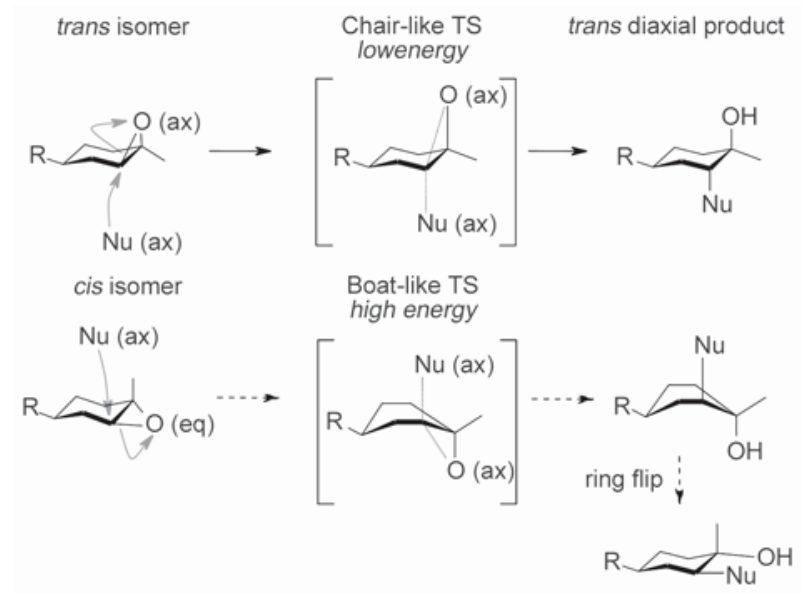

Figure 8. Mechanism of nucleophilic opening of epoxycyclohexane in LDO for trans and cis isomers. $\mathrm{Nu}=$ general nucleophile; $\mathrm{R}=2$-methyloxirane-2-yl; $\mathrm{ax}=$ axial; $\mathrm{eq}=$ equatorial; $\mathrm{TS}=$ transition state.
In case of the trans-isomers, this forms a favorable low energy 'chair-like' transition state. In contrast, the appropriate $c i s$-isomers would adopt a high energy 'twist-boat' conformation which does not react. In presence of catalysts the epoxy ring is activated, the conformational requirements, however, still outweigh as the performed experiments showed that only LDO's trans-isomers were reactive and that LDO's cis-isomers contain kinetically hindered endocyclic epoxides.

In addition reactions with amines, epoxides act as monofunctional groups, but in homopolymerizations such as anionic or cationic ring opening polymerizations epoxides react as bifunctional groups. Thus, in addition reactions with amines the presence of one non-reactive epoxy group in LDOs cis-isomers hinders the chain growth yielding viscous fluids. In the case of cationic ring opening polymerization, the cis LDO isomer is acting as a chain extender, while the trans-isomer is able to generate crosslinks resulting in a network if significant conversions of epoxide groups are achieved.

A better understanding of the polymerization behavior of the single LDO isomers will be necessary to enable LDOs technical application as a bio-based epoxy resin. As isomeric separation is considered to be impossible [22], diastereoselective epoxidation of limonene could help to obtain the single LDO isomers.

\section{Conclusions}

Commercial limonene dioxide has potential to be applied as a fully bio-based epoxy resin in a wide range of technical applications. It suffers, however from incomplete conversions during polymerization. We have investigated two different polymerization pathways, namely the Lewis acid catalyzed ring-opening polymerization and the polyaddition of LDO with amines. DSC and ${ }^{1} \mathrm{H}$ NMR studies showed that LDOs isomeric diversity hinders complete polymerization due to the low reactivity of the internal epoxide rings in $c i s$-isomers which is in agreement with the FürstPlattner rule or trans-diaxial effect.

\section{References}

[1] Anastas P. T., Warner J. C.: Green chemistry: Theory and practice. Oxford University Press, Oxford (1998).

[2] Cséfalvay E., Horváth I. T.: Chemicals from renewable feedstocks. AccessScience, Chemical Engineering. McGraw-Hill (2013).

https://doi.org/10.1036/1097-8542.YB130337 
[3] Zhu Y., Romain C., Williams C. K.: Sustainable polymers from renewable resources. Nature, 540, 354-362 (2016).

https://doi.org/10.1038/nature21001

[4] Bauer K., Garbe D., Surburg H.: Common fragrance and flavor materials: Preparation, properties and uses. Wiley-VCH, Weinheim (2001). https://doi.org/10.1002/3527600205

[5] Arizaga B., de Leon A., Burgueño N., López A., Paz D., Martínez N., Lorenzo D., Dellacassa E., Bussi J.: A clean process for the production of oxygenated limonene derivatives starting from orange oil. Journal of Chemical Technology and Biotechnology, 82, 532-538 (2007). https://doi.org/10.1002/jctb.1690

[6] Bähr M., Bitto A., Mülhaupt R.: Cyclic limonene dicarbonate as a new monomer for non-isocyanate oligo- and polyurethanes (NIPU) based upon terpenes. Green Chemistry, 14, 1447-1454 (2012).

https://doi.org/10.1039/c2gc35099h

[7] Byrne C. M., Allen S. D., Lobkovsky E. B., Coates G. W.: Alternating copolymerization of limonene oxide and carbon dioxide. Journal of the American Chemical Society, 126, 11404-11405 (2004).

https://doi.org/10.1021/ja0472580

[8] Hauenstein O., Reiter M., Agarwal S., Rieger B., Greiner A.: Bio-based polycarbonate from limonene oxide and $\mathrm{CO}_{2}$ with high molecular weight, excellent thermal resistance, hardness and transparency. Green Chemistry, 18, 760-770 (2016). https://doi.org/10.1039/C5GC01694K

[9] Crivello J. V.: Investigations of the reactivity of 'kickstarted' oxetanes in photoinitiated cationic polymerization. Journal of Polymer Science Part A: Polymer Chemistry, 53, 586-593 (2015). https://doi.org/10.1002/pola.27479

[10] Lalevée J., Fouassier J. P.: Recent advances in sunlight induced polymerization: Role of new photoinitiating systems based on the silyl radical chemistry. Polymer Chemistry, 2, 1107-1113 (2011). https://doi.org/10.1039/c1py00073j

[11] Lalevée J., Mokbel H., Fouassier J-P.: Recent developments of versatile photoinitiating systems for cationic ring opening polymerization operating at any wavelengths and under low light intensity sources. Molecules, 20, 7201-7221 (2015).

https://doi.org/10.3390/molecules20047201

[12] Tehfe M-A., Lalevée J., Gigmes D., Fouassier J. P.: Green chemistry: Sunlight-induced cationic polymerization of renewable epoxy monomers under air. Macromolecules, 43, 1364-1370 (2010). https://doi.org/10.1021/ma9025702
[13] Crivello J. V.: Radical-promoted visible light photoinitiated cationic polymerization of epoxides. Journal of Macromolecular Science Part A: Pure and Applied Chemistry, 46, 474-483 (2009). https://doi.org/10.1080/10601320902797707

[14] Pattenden G.: Comprehensive organic synthesis, Vol 3: Carbon-carbon bond formation. Pergamon, Saint Louis (1992).

[15] Mukhamedova L. A., Kudryavtseva M. I., Martynov A. A.: Reaction of limonene dioxide with ethanol. Russian Chemical Bulletin, 23, 370-373 (1974). https://doi.org/10.1007/BF00924690

[16] Chen C. S., Pearce E. M.: The boron trifluoride monoethyl amine complex cured epoxy resins. Journal of Applied Polymer Science, 37, 1105-1124 (1989). https://doi.org/10.1002/app.1989.070370421

[17] Elvers B.: Ullmann's polymers and plastics: Products and processes. Wiley-VCH, Weinheim (2016).

[18] Chrisman W., Camara J. N., Marcellini K., Singaram B., Goralski C. T., Hasha D. L., Rudolf P. R., Nicholson L. W., Borodychuk K. K.: A simple and convenient synthesis of $\beta$-amino alcohol chiral auxiliaries based on limonene oxide. Tetrahedron Letters, 42, 5805-5807 (2001).

https://doi.org/10.1016/S0040-4039(01)01135-2

[19] Caraman R. M., Klika K. D.: ChemInform abstract: The four diepoxides of (R)-(+)-limonene. ChemInform, 23, 1803-1808 (1992). https://doi.org/10.1002/chin.199210248

[20] Fürst A., Plattner P. A.: Über Steroide und Sexualhormone. 160. Mitteilung. $2 \alpha, 3 \alpha$ - und $2 \beta, 3 \beta$-oxidochlolestane; Konfiguration der 2-oxy-cholestane (in German). Helvetica Chimica Acta, 32, 275-283 (1949). https://doi.org/10.1002/hlca.19490320139

[21] Raban M., Burch D. L., Hortelano E. R., Durocher D., Kost D.: Complete conformational switching in a calcium ionophore. Journal of Organic Chemistry, 59, 12831287 (1994). https://doi.org/10.1021/jo00085a014

[22] Newhall W. F.: Derivatives of (+)-limonene. III. A stereospecific synthesis of cis- and trans- $\Delta^{8(9)}$-p-menthene 1,2-epoxides. Journal of Organic Chemistry, 29, 185187 (1964). https://doi.org/10.1021/jo01024a042 